\title{
Exit Poll Sponsorship and Response Intentions
}

\author{
Costas Panagopoulos ${ }^{1}$ \\ ${ }^{1}$ Department of Political Science, Fordham University, Bronx, NY, United States \\ Correspondence: Costas Panagopoulos, Department of Political Science, Fordham University, 441 E. Fordham \\ Rd., Bronx, NY 10458, United States. Tel: 1-718-817-3967. E-mail: costas@post.harvard.edu
}

Received: March 17, 2016 Accepted: April 8, 2016 Online Published: May 29, 2016

doi:10.5539/jpl.v9n4p72

URL: http://dx.doi.org/10.5539/jpl.v9n4p72

\begin{abstract}
Scholars and practitioners alike are increasingly concerned about growing and differential rates of nonresponse in exit polls. In this paper, I examine how exit poll sponsorship affects response intentions. I leverage an experiment imbedded in a nationally-representative probability sample telephone sample that probed respondents about exit poll participation intentions. The survey, fielded by Opinion Research Corporation for CNN in November 2006, randomly varied whether respondents were informed the exit poll would be conducted by the "television networks," specifically, or generically, by "some organizations." The results reveal that respondents are significantly more likely to report they would be likely to participate in exit polls when television networks are explicitly identified as sponsors. These effects are robust across a series of specifications and do not appear to be moderated by key observable attributes including age, gender, race, partisanship or educational attainment.
\end{abstract}

Keywords: exit polls, surveys, nonresponse, survey experiment

\section{Introduction}

Declining survey response rates are a growing concern in the United States and elsewhere (Keeter, 2011). Systematic differences between respondents and nonrespondents can potentially compromise the quality of survey results. While several studies demonstrate that attitudes and traits between these two groups often do not differ substantially, significant differences can emerge (Curtin, Presser, \& Singer, 2000, 2010; Keeter, Miller, Kohut, Groves, \& Presser, 2000; Keeter, 2011). Nonresponse is especially acute with telephone surveys due to both noncontact and refusals (Zukin, 2006) Keeter (2011) reports response rates for telephone surveys conducted by the Pew Research Center have declined by about two percentage points on average per year, a rate similar to what has been documented in other similar surveys.

In the context of exit polling, population parameters can be compared against estimated statistics to assess the degree of survey error attributable to nonresponse (Bautista, Callegaro, Vera, \& Abundis, 2007). Some studies detect no relationship between signed error and nonresponse rates in exit polls (Merkle \& Edelman, 2000, 2002; Mitofsky, 2005). More recently, however, exit poll nonresponse has increased and differences between exit poll estimates and actual vote distributions, measured as "within precinct error," are on the rise (Traugott, Highton, \& Brady, 2005; Frankovic, Panagopoulos, \& Shapiro, 2009). Evidence of differential nonresponse in exit polls is accumulating (Frankovic, Panagopoulos, \& Shapiro, 2009; Merkle \& Edelman, 2000, 2002; Mitofsky, 2005; Keeter, 2011; McDonald \& Thornburg, 2012; Panagopoulos, 2013). For example, comparisons of precinct-level votes and exit polls in the same precincts in some states showed that Democrats were more likely than Republicans to consent to interviews in both 2004 and 2006 (Keeter, 2011). Joe Lenski, who manages the exit poll operation for Edison Mitofsky Research has observed that, "exit poll inaccuracy tends to happen in very partisan, very polarized, very active electorate races" (quoted in Keeter, 2011: 32), which are characteristics common to recent election cycles.

To complicate matters, substantial and growing rates of early and mail-in (including absentee) voting in many states across the country present special challenges for exit polling. In the 2008 presidential election cycle, nearly one-third (32.7 percent) of all votes cast were cast early or by mail before Election Day (Mokrzycki, Keeter, \& Kennedy, 2009). These developments have led exit pollsters to supplement traditional precinct-based surveying with surveys conducted via telephone in order to maximize coverage. In 2008, Edison Research conducted over 15,000 telephone interviews in 18 states across the country to measure early or mail-in voting 


\section{(Mokrzycki, Keeter, \& Kennedy, 2009). ${ }^{1}$}

Telephone surveys raise further concerns about survey quality given potential challenges in reaching cell-phone only populations which, by the second half of 2008, accounted for 20 percent of households (Blumberg \& Luke, 2009). A study that compared the demographic attributes and political preferences of voters in 2008 by telephone status found significant differences. Polls that excluded wireless telephone users were prone to a pro-Republican bias, underestimating Obama support by about 2 percentage points on average (Keeter, Kiley, Christian, \& Dimock, 2009).

\section{Sponsorship and Survey Response: Theory and Hypotheses}

In such a scenario, it is useful to ask whether there exist strategies that have the potential to raise exit poll response rates. Research in social psychology has identified a number of psychological factors that affect compliance with survey participation requests. Cialdini (1988) proposes that individuals reply primarily on six compliance principles to determine whether they will yield to such requests: reciprocation, consistency, social validation authority, scarcity, and liking. In this study, I focus on two of these principles: authority and liking. With respect to the former, scholars argue that people are more likely to comply with a request if it comes from a properly constituted authority perceived to be legitimate (Groves, Cialdini, \& Couper, 1992: 483; Bickman, 1974; Bushman, 1984; Milgram, 1974), or someone who is sanctioned by the society to make such requests and to expect compliance. Groves, Cialdini, \& Couper (1992: 483) argue that, "[i]n the survey context, the immediate requester is typically not the authority figure but is seen as representing some sponsoring organization that can be judged to have varying degrees of authority status. One would expect that interviewers who emphasize the sponsor of their survey will be more successful in generating participation if the sponsor is generally seen as having legitimate authority to collect the information (e.g., government or educational institutions), but that this effect will be reversed if the sponsor is not seen as having such status (e.g., certain commercial organizations). Cialdini (1988) also emphasizes "liking" as a compliance heuristic. This principle implies individuals should be more willing to comply with requests from individuals or sponsoring organizations perceived favorably.

Both of these principles imply the sponsoring organization is a crucial element that has the potential to play a prominent role in influencing compliance decisions with exit poll participation requests. In this study, I focus on how exit poll response intentions vary depending on the sponsor. In particular, I examine the impact of informing prospective respondents that exit polls will be conducted specifically by television networks, compared to unspecified organizations. As commercial enterprises, one could interpret Cialdini's (1988) claims to suggest prospective survey subjects may perceive television networks as illegitimate sponsors, thereby depressing compliance expectations. Although Americans are accustomed to television networks sponsoring exit polls, which they have been doing since the $1960 \mathrm{~s}^{2}$, and they generally rely most heavily on televised news media outlets to acquire information about politics and elections (Wayne, 2007), it is unclear whether television networks possess the requisite authority to secure heightened compliance levels in terms of exit poll survey participation compared to alternative entities. Beyond that, I also argue that the public is less favorably disposed to media institutions, generally, especially as compared with other institutions. Although confidence in public institutions has eroded across the board in American society over the past few decades, the decline in confidence in media organizations, and television news media in particular, has been especially acute (Kasniunas, 2008; Moy \& Pfau, 2000). Accordingly, on the basis of claims advance by Cialdini (1988) in terms of both authority and liking, I hypothesize that citizens will be less likely to participate in exit polls if they are aware the surveys are sponsored by television networks compared to other types of sponsoring organizations. I test this hypothesis with a survey experiment described in the following section.

\section{Experimental Design and Sample}

In November 2006, the Opinion Research Corporation probed respondents in a nationally-representative, probability sample, RDD survey conducted by telephone on behalf of CNN about exit poll participation intentions. The survey was designed as a split sample in which respondents were randomly assigned to one of two versions of the key survey item. Approximately half $(N=476)$ of the respondents were asked: "Every election, the television networks conduct exit polls of people as they leave their polling places on Election Day. If you were asked to participate, how likely is it you would be willing to spend 10 minutes filling out a

\footnotetext{
${ }^{1}$ I acknowledge that a key advantage to precinct-based exit poll surveys is that it is unnecessary to rely on self-reported voting as in parallel, telephone-based exit poll surveys.

${ }^{2}$ In 2003, the National Election Pool, a consortium of the five major television networks (NBC, CBS, NBC, CNN and Fox) along with the Associated Press, was formed to conduct exit polls.
} 
questionnaire - very likely, somewhat likely, not very likely, or not likely at all?"3 The other half of the sample $(N=467)$ was asked the identical question, although "television networks" was replaced with "some organizations." 4

Table 1 confirms that the randomization procedure generated experimental groups that were balanced in terms of observable characteristics including gender, age, race, educational attainment and partisanship. Balance can also be confirmed statistically. An OLS regression that predicts assignment to the experimental conditions as a function of the five covariates is, as expected, insignificant at conventional levels $(F(4,916)=.85, p=.49)$.

Table 1. Randomization check

\begin{tabular}{llll}
\hline \multicolumn{3}{c}{ Sponsorship } \\
\hline Attribute & Television Networks & Some Organizations & Prob $>$ F $^{\text {a }}$ \\
\hline Female & 50.2 & 51.6 & .67 \\
Age (Years) & 53.8 & 53.6 & .80 \\
White & 85.3 & 85.2 & .98 \\
Education (College Grad) & 45.0 & 41.4 & .26 \\
Democrat & 32.3 & 35.8 & .25 \\
\hline
\end{tabular}

NOTES: Figures in columns represent mean percentages unless otherwise indicated.

${ }^{a}$ Test statistics generated using one way ANOVA to evaluate whether mean turnout levels differ across categories of random assignment. In all cases, I cannot reject the hypothesis of equal means at standard significance levels $(\mathrm{p}<.05)$, implying balance across groups.

\section{Experimental Results}

For simplicity, I collapsed the response categories in this study to create a dichotomous measure of exit poll participation intent: "very likely" and "somewhat likely" were combined and categorized as "likely" to participate, while "not very likely" and "not likely at all" were combined and categorized as "unlikely." Overall, I find that 68.6 percent of respondents assigned to the "television networks" condition indicated they would be likely to participate in exit polls, compared to 62.6 percent of respondents in the alternative condition. This implies a positive treatment effect of 6.0 percentage points (standard error=3.1) for the television networks version of the treatment. I note this effect is statistically significant at conventional levels $(p<.05)$, suggesting respondents informed exit polls would be conducted by the television networks are significantly more likely to report willingness to participate compared to being informed exit polls would be conducted by unspecified organizations.

I acknowledge that social desirability response bias is potentially a concern in the current study, which relies on respondents' self-reported likelihood to participate in exit polls. Our overall results suggest the prospects for exit poll participation among respondents in our sample were more optimistic compared to compliance in the actual surveys. In reality, Edison Media Research, the organization that conducted the National Election Poll (NEP) for the broadcast networks in 2008, reported a response rate of 46 percent for sample precincts and 29 percent for the phone surveys (McDonald \& Thornburg, 2012). Despite the fact that exit poll participation intentions were likely overstated in our sample, the experimental nature of the current study allows us to assume any proneness to report socially-desirable responses is evenly distributed across our experimental conditions. As such, it would not bias the overall treatment effects I detect.

For more rigorous analysis of the experimental results, I use multiple regression (OLS) to obtain estimates of the

\footnotetext{
${ }^{3} \mathrm{CNN} / \mathrm{ORC}$ surveyed a total of 1,025 adults nationally between November 17-19, 2006. I restrict the analyses to registered voters.

${ }^{4}$ I emphasize that neither $\mathrm{CNN}$ nor any other media organization was identified the sponsor of the survey, thereby alleviating concerns that respondents could have been primed or biased as a results. The following is the script used by interviewers to introduce the survey: "Hello, my name is _. I'm calling from Opinion Research Corporation of Princeton, New Jersey. We're conducting a national survey of people's opinions on subjects of interest to the American Public and would like to have your household participate. We are not selling any products or services. We are only asking your opinions. Yout answers will remain confidential."
} 
treatment effects ${ }^{5}$. This approach permits the inclusion of control variables to correct for imbalances between experimental groups due to chance. I estimate two models: Equation 1 expresses individual exit poll participation intention as a linear function of the experimental treatment conditions. The results of a linear regression in which exit poll participation intent $\left(Y_{i}\right)$ for individual $i$ is regressed on a dummy variable $\left\{D_{l i}\right\}$ denoting the "television networks" treatment are presented in the first column of Table 2. This model may be written simply as: $Y_{i}=\beta_{0}+\beta_{1} D_{1 i}+u_{i}$, (equation 1) where $u_{i}$ represents an unobserved disturbance term.

Equation 2 is embellished to include the battery of available covariates. The inclusion of covariates is optional, but it may reduce the disturbance variance and improve the statistical precision of the estimated treatment effects. The model may be written as: $Y_{i}=\beta_{0}+\beta_{1} D_{1 i}+\lambda_{1} V_{1 i}+\ldots+\lambda_{t} V_{t i}+u_{i}$ (equation 2) where $(\lambda)$ s represent parameters associated with each covariate $(V)$, and $u_{i}$ represents an unobserved disturbance term. The results are presented in the second column of Table 2.

Table 2. Exit poll sponsorship and response intentions

\begin{tabular}{lll}
\hline & $\begin{array}{l}\text { CNN/ORC } \\
\text { (November 2006) }\end{array}$ \\
\hline Variable & Excludes Covariates & $\begin{array}{l}\text { Includes } \\
\text { Covariates }\end{array}$ \\
\hline $\begin{array}{l}\text { Sponsorship Treatment } \\
\text { (TV Networks=1, 0 otherwise) }\end{array}$ & $.060(.031)^{* *}$ & $.076(.031)^{* *}$ \\
\hline Age (Years) & & $-.004(.001)^{* * *}$ \\
Female & & $.033(.031)$ \\
White & & $-.034(.045)$ \\
Democrat & $.088(.034)^{* * *}$ \\
Education (College graduate=1,0 otherwise) & & $.010(.032)$ \\
\hline$N$ of individuals & 936 & 903 \\
\hline RMSE & .475 & .466 \\
\hline
\end{tabular}

NOTES: OLS regression (unweighted). Dependent variable is coded 1 if respondent reported it was likely they would participate in an exit poll, 0 otherwise. Standard errors in parentheses. $* * *$ denotes statistical significance at the $\mathrm{p}<.01$, and $* *$ at the $\mathrm{p}<.05$ levels using two-tailed tests.

The regression results parallel the initial findings. The estimations reveal that subjects exposed to the "television networks" version of the stimulus reported significantly higher levels of exit poll participation intentions, relative to those who were informed the surveys would be conducted simply by "some organizations." Estimates of the treatment effects across the two specifications are quite robust; the addition of covariates (Model 2) adjusts the estimates upward modestly. The results imply exposure to the "television networks" treatment elevated compliance intentions by 7.6 percentage points on average, an effect that is statistically significant at the $\mathrm{p}<.05$ level.

Having confirmed that reported exit poll compliance intentions are reliably higher for respondents who are informed the television networks would conduct these surveys, compared simply to "some organizations," it is useful to consider whether this effect differs across respondent types. Such heterogeneity, if present, would presumably result in differential response that would likely produce bias in the exit poll preference distributions. To advance such an analysis, I estimate a parallel regression model in which I include a series of terms interacting the [television networks] treatment with each of the five covariates included in our analyses. I find that none of the interaction terms are statistically significant at conventional levels (not shown but available from the authors upon request), implying the effects I observe are homogeneous. Accordingly, I interpret these results to suggest there is little reason to be concerned about differential exit poll compliance rates attributable to sponsorship.

\footnotetext{
${ }^{5}$ For ease of interpretation, I use OLS regression to estimate models. Using alternative estimation procedures (e.g., probit or logistic regression) does not substantively alter the results reported below. Details are available from the authors upon request.
} 


\section{Conclusion}

I leverage a survey experiment imbedded in a nationally-representative probability telephone sample to assess how exit poll sponsorship affects compliance intentions. Overall, I find that exit poll sponsorship matters in terms of likely compliance to participate. The results reveal that respondents are significantly more likely to report they are likely to participate in exit polls when television networks are explicitly indentified as sponsors. These effects are robust across a series of specifications and do not appear to be moderated by key observable attributes including age, gender, race, partisanship or educational attainment. I conclude from these findings that television network sponsorship of exit polls likely results in higher response rates across the board, thereby minimizing noncoverage. Moreover, the results suggest there is little reason to be concerned about bias resulting from differential response attributable to sponsorship type. The implications of these findings are of relevance particularly to exit pollsters, but they may also speak more broadly to strategies that could potentially raise compliance in surveys overall. In an era of dwindling response rates, these implications are potentially far-reaching.

The conclusions I draw from the results reported in the current study reflect some promising insights into how exit poll sponsorship influences compliance levels, but it is important to acknowledge and to consider how recent developments in the sociopolitical landscape may affect exit poll compliance considerations. One key development is the dramatic growth in early, convenience, no-fault absentee or mail voting. How sponsorship effects interact with these changes in terms of exit poll participation remains an open question. It is conceivable that exit poll sponsorship matters less (or more) for individuals recruited to participate by telephone compared to precinct locations. These possibilities and their implications warrant further study.

\section{References}

Abramson, P., Aldrich, J., \& Rohde, D. (2012). Change and Continuity in the 2008 and 2010 Elections. Washington, DC: CQ Press.

Atkeson, L. R. (2010). The State of Survey Research as a Research Tool in American Politics. In Jan E. Leighley (Ed.), The Oxford Handbook of American Elections and Political Behavior. New York: Oxford University Press. http://dx.doi.org/10.1093/oxfordhb/9780199235476.003.0002

Belli, R. F., Traugott, M. W., \& Beckmann, M. N. (2001). What Leads to Voting Overreports? Contrasts of Overreporters to Validated Voters and Admitted Nonvoters in the American National Election Studies. Journal of Official Statistics, 17(4), 479-498.

Bernstein, R., Chadha, A., \& Montjoy, R. (2001). Overreporting Voting: Why It Happens and Why It Matters. Public Opinion Quarterly, 65, 22-44. http://dx.doi.org/10.1086/320036

Curtin, R., Presser, S., \& Singer, E. (2000). The Effects of Response Rate Changes on the Index of Consumer Sentiment. Public Opinion Quarterly, 64, 413-428. http://dx.doi.org/10.1086/318638

Curtin, R., Presser, S., \& Singer, E. (2010). Changes in Telephone Survey Nonresponse over the Past Quarter Century. Public Opinion Quarterly, 69(1), 87-98. http://dx.doi.org/10.1093/poq/nfi002

Frankovic, K., Panagopoulos, C., \& Shapiro, R. (2009). Opinion and Election Polls. In D. Pfeffermann, \& C. R. Rao (Eds.), Handbook of Statistics-Sample Surveys: Design Methods and Applications, Volume $29 \mathrm{~A}$ (pp.567-596). Netherlands: Elsevier. http://dx.doi.org/10.1016/S0169-7161(08)00022-9

Groves, R. (2006). Nonresponse Rates and Nonresponse Bias in Household Surveys. Public Opinion Quarterly, 70(5), 646-675. http://dx.doi.org/10.1093/poq/nfl033

Hill, S., Lo, J., Vavreck, L., \& Zaller, J. (2007). The Opt-in Internet Panel: Survey Mode, Sampling Methodology and the Implications for Political Research. Paper presented at the Annual Meeting of the Midwest Political Science Association, Chicago, IL: April 12.

Holbrook, A., \& Krosnick, J. (2010). Social Desirability Bias in Voter Turnout Reports: Tests Using the Item Count Technique. Public Opinion Quarterly, 74(1), 37-67. http://dx.doi.org/10.1093/poq/nfp065

Kasniunas, N. T. (2008). The Gatekeeping Power of the Media as Illustrated in Its Coverage of Civil Rights and Liberties. In M. Rozell, \& J. Mayer (Eds.), Media Power, Media Politics (2nd ed.). Lanham, MD: Rowman \& Littlefield.

Keeter, S. (2011). Public Opinion Polling and Its Problems. In K. Goidel (Ed.), Political Polling in the Digital Age: The Challenge of Measuring and Understanding Public Opinion. Baton Rouge: Louisiana State University Press. 
Keeter, S., Kiley, J., Christian, L., \& Dimock, M. (2009). Perils of Polling in the 2008 Election. Paper presented at the Annual Meeting of the American Association for Public Opinion Research. Hollywood, FL: May 14-17.

Keeter, S., Miller, C., Kohut, A., Groves, R. M., \& Presser, S. (2000). Consequences of Reducing Nonresponse in a Large National Telephone Survey. Public Opinion Quarterly, 64, 125-148. http://dx.doi.org/10.1086/317759

Malhotra, N., \& Krosnick, J. A. (2007). The Effect of Survey Mode and Sampling on Inferences About Political Attitudes and Behavior: Comparing the 2000 and 2004 ANES to Internet Surveys with Nonprobability Samples. Political Analysis, 15, 286-324. http://dx.doi.org/10.1093/pan/mpm003

McDonald, M. (2009). The Return of the Voter: Voter Turnout in the 2008 Presidential Election. The Forum, 6(4), 1-12. http://dx.doi.org/10.2202/1540-8884.1278

McDonald, M., \& Thornburg, M. (2012). Interview Mode Effects: The Case of Exit Polls and Early Voting. Public Opinion Quarterly, 76(2), 326-349. http://dx.doi.org/10.1093/poq/nfs025

Merkle, D. M., \& Edelman, M. (2000). A Review of the 1996 Voter News Service Exit Polls from a Total Survey Error Perspective. In P. J. Lavrakas, \& M. W. Traugott (Eds.), Election Polls, the News Media and Democracy (pp. 68-92). New York: Chatam House.

Merkle, D. M., \& Edelman, M. (2002). Nonresponse in Exit Polls. A Comprehensive Analysis. In R. M. Groves, D. A. Dillman, J. L. Eltinge, \& R. J. A. Little (Eds.), Survey Nonresponse (pp. 243-257). New York: Wiley.

Mitofsky, W. J. (2005). 2004 Exit Polls. Paper presented at the 60th Annual Conference of the American Association for Public Opinion Research (AAPOR), Miami, FL. (May).

Mokrzycki, M., Keeter, S., \& Kennedy, C. (2009). Cell-Phone-Only Voters in the 2008 Exit Poll and Implications for Future Noncoverage Bias. Public Opinion Quarterly, 73(5), 845-865. http://dx.doi.org/10.1093/poq/nfp081

Moy, P., \& Pfau, M. (2000). With Malice Towards All? The Media and Public Confidence in Democratic Institutions. Westport, CT: Praeger.

Panagopoulos, C. (2013). Who Participates in Exit Polls? Journal of Elections, Public Opinion and Parties, 23(4), 444-455. http://dx.doi.org/10.1080/17457289.2013.811585

Popkin, S., \& McDonald, M. (1998). Who Votes? Blueprint: Ideas for a New Century, 1, 28-29.

Traugott, M., Highton, B., \& Brady, H. E. (2005). A Review of Recent Controversies Concerning the 2004 Presidential Election Exit Polls. The National Election Commission on Elections and Voting, Social Science Research Council, New York, March 10.

Wayne, S. (2007). Is This Any Way to Run a Democratic Election? (3rd ed.). Washington, DC: CQ Press.

Zukin, C. (2006). The Future Is Here! Where Are We Now? And How Do We Get There? Public Opinion Quarterly, 70(3), 426-442. http://dx.doi.org/10.1093/poq/nfl009

\section{Copyrights}

Copyright for this article is retained by the author(s), with first publication rights granted to the journal.

This is an open-access article distributed under the terms and conditions of the Creative Commons Attribution license (http://creativecommons.org/licenses/by/3.0/). 